\title{
The Gnosjo industrial district: a viable corporation
}

\section{Reza Mohammady Garfamy}

Faculty of Economics and Management, Semnan University, University Square, Semnan 35131-19111, Iran

E-mail: garfamy@yahoo.com

\begin{abstract}
The Gnosjo region is unique in Sweden and renowned for its distinctive business climate, which is termed a progressive, entrepreneurial and innovative 'spirit of Gnosjo'. This paper presents a special image of the industrial district relationships in this region by using the corporation as a framework to understand the structuring of business activities with respect to the content (what) and the process (how). The findings indicate viability of the industrial district is based and dependent on economic and social organisation. The paper also suggests possible directions for future policies and research to support the dynamic growth in this region by using an alternative perspective in analysing and explaining the industrial district phenomenon.
\end{abstract}

Keywords: industrial district; corporation; entrepreneurship; small and medium-sized enterprises; SMEs; transaction cost; community; regional economic development; Gnosjo; Sweden.

Reference to this paper should be made as follows: Mohammady Garfamy, R. (2011) 'The Gnosjo industrial district: a viable corporation', Int. J. Entrepreneurship and Small Business, Vol. 13, No. 2, pp.220-234.

Biographical notes: Reza Mohammady Garfamy received his $\mathrm{PhD}$ in Business Creation, Strategy and Management, MSc in Industrial Engineering (System and Productivity Management) and BSc in Mathematics (Applied in Computer). His current research interests include entrepreneurship and its implications. He has published many books and papers in international journals.

\section{Introduction}

The Gnosjo region is a phenomenon among the industrial districts. It is the only genuine industrial district in Sweden and it is famous for its spirit in the world. The Gnosjo industrial district includes a powerful group of small and medium-sized enterprises (SMEs) that has a relatively tight interaction and unbounded communication between economic and social lives where specialised businesses are deeply embedded. The spirit of Gnosjo embraces all capitals developed in the interaction with local production environments. This collective spirit includes certain unique features that make it the lifeblood of the region (Johannisson, 2002; Wigren, 2003).

A variety of changes has reached the Gnosjo region in the form of increasing immigration because of a high demand for workforce and the selling of local firms to the externally-owned international firms (Wigren, 2003). The consequences of increasing external ownership of industrial businesses are causing several changes in the economic 
and social lives of the region. In this tandem, Wigren (2003) has found some ramifications such as reframing new social rules by new actors who influence the business life.

These changes are transforming the basis of this extraordinary region into new dimensions that erode the cornerstones of its traditions. In order to maintain and improve its current competitive advantage, it has to be aware of the exchange-related issues and form a viable and unanimous unit able to compete on the global market in the future.

Therefore, it is essential to understand and evaluate the consequences of changes on the viability of this industrial district in the whirlpool of a globalising world in regard to the structuring of business activities according to the content (technology, learning and local/non-local ownership) and the process (personal/inter-organisational relationships and ongoing economic and social changes) using the conceptual framework of corporation.

\section{Research description}

\subsection{Literature review}

The industrialised countries have been in a process of industrial restructuring where the well-being of a region in a successful organisation has been welling up from a particularly effective economic and social organisation based on SMEs. This organisation is a crucial characteristic of an industrial district as a dynamic approach to the regional economic development. An essential concept of the local economic regeneration is the industrial district which is defined as the networks of SMEs that are linked to one another in the local institutions and share resources to form the innovative and productive industrial organisations, and they are therefore of a strong competitive advantage (Sengenberger and Pyke, 1992). In other words, an industrial district is a geographically-localised productive system based on an extended division of labour between SMEs that are specialised in distinct phases of a common industrial sector.

Trigilia (1992) brings out three institutional factors that have crucial importance in the growth of industrial districts. These factors, in their typical forms in the classical case of small business regions of the Third Italy, are as follows:

- SMEs network of urban centres with industrial tradition

- $\quad$ supply of flexible and inexpensive workforce from family-based smallholdings

- local religious and political movement tradition.

Hence, both economic and social factors moulding an industrial district intertwine in the formal and informal networks of a region and its industries. The stakeholders' formal and informal relations in an agglomerated region form the embedded sediment required to maintain and facilitate the economic development of an industrial district. However, these relations are motivated by the desire to reduce the transaction costs of exchange (Serarols i Tarres et al., 2008).

The key principles for the success of an industrial district include the strong networks in the same industrial sector, geographical proximity, readiness for cooperation, entrepreneurial dynamism, flexible specialisation, qualified workforce and trust. Entrepreneurial bodies using these principal rules are usually geographically-bounded. 
Consequently, the proximity between individuals, firms and institutions improves the effectiveness of several functions such as innovation, collaboration, cohesion and a sense of collective consciousness (Sengenberger and Pyke, 1992). This kind of organisation thus purports the way by which the business units are organised together to be more efficient, effective and flexible.

Karlsson and Larsson (1993), in research about the long-run sustainability of the Gnosjo phenomenon during the period 1980-88, found that the phenomenon had not been as successful as expected. They suggested that labour-intensive industries should be structured more in the knowledge-intensive direction to sustain and improve the competitiveness of industries in the region in the long run.

The reason why international firms are so interested in setting up some branches in these kinds of flourishing industrial districts is their enormous and valuable pool of capital. The complementary forms of capital enforcing entrepreneurship in an industrial district are the financial (formal and informal financing), human (collaboration between academics and practitioners) and social (used trust in collaborating and clustering functionally, spatially and virtually). It is realistic to think that an economic interaction requires all of these capital forms to succeed in the best possible way (Johannisson, 2004).

Wigren (2003) has found that the increasing external ownership in Gnosjo has become a controversial question among the people. The first firms that were sold to the external investment firms in the 1980s were Finnveden and Gnosjo-Borsen. The former owners who have stayed as CEOs in the growing and developing firms seem to be content with the new arrangement. In general, the ultimate aim of external take over is to provide the business with a global direction. Another aspect is a high expectation for better turnovers and profits in the boards of investment firms. Wigren (2003) has weighed further the pros and cons of selling the businesses of the region to external actors. The advantages of the region are as follows:

- external firms provide new economic investments, relations and networks

- new firms bring in their global market links.

On the other hand, the disadvantages of the region are both economic and social as follows:

- The approaches to economic life are different in locally- and externally-owned firms. The local owners run their businesses from a social perspective and prefer the community to profit while the managers of investment firms, by making the plan in the holding company and distributing the work to subsidiary firms, do not necessarily commit to the region.

- External ownership threatens the social life of the community. The socially important projects require much persuasion by the community to get the externally-owned firms involved because their leaders are almost invisible. This new style makes the decision making typically hierarchical and slow.

However, the business community at large benefits from both the dense local networks that absorb the external influences and the globally significant firms that provide competitive strength to all individual firms (Johannisson et al., 2002). 


\subsection{Purpose of study and main research question}

The purpose of this study is to evaluate the viability of the Gnosjo industrial district in the competitive market by using the concept of corporation as a main conceptual framework. The focus is also on the content and process of the structuring of business activities in the region. The research seeks to answer the following question: What is the viability of corporation in the Gnosjo industrial district?

We address this question by searching the answers to the following sub-questions:

- What specific hierarchies exist in the Gnosjo industrial district?

- What specific factors affect the transaction costs of exchange in that industrial district?

Furthermore, it is also interesting to find what factors direct the mutual strategy of the region.

\subsection{Limitations of study}

The limitations of research arise from considering the economic changes rather than the social ones and concentrating on the hierarchies rather than networks. We focus mainly on examining those stakeholders operating mostly in profit business interactions including SMEs and local branches of international firms. The public authorities and non-profit organisations are also mentioned in the context of formal networks. However, the generalisability of research results can occur at the level of analytic generalisation only (Yin, 2003). Despite these limitations, the stakeholders inside and outside of the region can benefit from the research results in planning for the future of these kinds of industrial districts.

\section{Theoretical framework}

\subsection{Corporation view}

Individual actions and emerging organisations produce a range of institutions in a society. Sjostrand (1992) considers the institution as a basic emergent form or infrastructure that facilitates (or hinders) the human (interaction and exchange) coordination and resource (re)allocation. The organisation can thus be conceived as a process affected by institutions. Therefore, the institutions are both the medium of organising and the outcome of it to reduce the fundamental uncertainty and facilitate the effective and legitimate coordination of human actions in the society.

There were two institutional approaches that dominated the 1990s: one focused on the legalities and constructions and the other on the human actions with their rationales. In the framework of institution developed by Sjostrand (1992), there are two dimensions of human interaction; namely, the rationale of interaction and the form of organising it. The rationale is divided into calculative, ideational and genuine exchanges while the forms are hierarchy and network. In this research, we concentrate on a theoretical category deduced from an interaction pattern consisting of both a calculative rationale and a hierarchical form that is called 'corporation' (Sjostrand, 1992). 
Individuals have both economic and social motives to act and form relationships (Granovetter, 1992). Similarly, Etzioni [1988, cited in Sjostrand (1992)] stresses that individual actions are rational in the calculative (technical or economic) sense and are highly influenced by moral considerations (values or ideals). The primary purpose of an action reveals the rationale behind the interaction (Sjostrand, 1992) that can be on a continuum from a true homo-economicus (thinking only about money); to the other end of a homo-spiritualis (valuing only saving other's souls). It can also be caretaking in a rational and considerate way. These types of actions create a social capital in a region as a growth platform for business agglomeration (Furst et al., 2001; Johannisson, 2004).

The pure hierarchy is a system of asymmetrical relationships where individuals are organised into different levels of importance in superiority and subordination. The hierarchy expresses the power relations and distributions in the exchanges between individuals. The routines of norms and ideals for interaction are hereby encouraged by communes and hierarchies [Butler (1983) cited in Sjostrand (1992)]. The mutual interaction between individuals and institutions proceeds according to existing, unrelated and even conflicting norms, values and rationalities reflecting in the talk and action of members in a specific organisation (Sjostrand, 1992). The relations between individuals and organisations contribute to the basic forms for exchange interaction. The embeddedness of personal and economic relations of individuals in a region promotes the actions of firms, trade associations, trade unions, educational institutions and local governments (Benton, 1992).

The logic of corporation as a normative structure usually pervades or infuses all the organisations and thus, there are (re)distribution and reciprocal relationships developing the change constantly.

\subsection{Transaction costs in corporation}

Transaction cost approach emphasises that it is transaction rather than technology that determines the efficacy and efficiency of an exchange by one mode of organisation as compared with another (market or internal organisation). According to Williamson (1979), an efficient economic organisation matches the governance structure of transactional attributes such as the frequency of exchange, transaction specificity and uncertainty. However, a transaction has three stages including contacting, contracting and controlling the exchange. In this respect, he recognises the classical, neoclassical and relational categories of contract.

Transaction costs are influenced by bounded rationality, opportunism and uncertainty (Nooteboom, 1993). The scarcity and cost of information alongside the limited capacity for information processing cause bounded rationality. Additionally, the inability of parties in an exchange to conceive all the possible contingencies gives space to the opportunistic behaviour. To organise the transactions, the parties can rely on either different ways of contracting or trust-based commitments or both. The situation where the transaction costs are low can be predicted by the absence of opportunism and presence of trust that lead to the cooperation and mutual benefits. Low transaction costs are also connected to the governance structure. In hierarchical environments, the risks are smaller because there is more control.

Rationality is much more bounded in smaller firms than larger ones because of fewer functional areas in staff support (width), lower level of education with the exception of science-based industries (depth) and dominance of the entrepreneur's personal view 
(variety). The value of transaction relations will be increased in a turbulent environment if the learning is considered. In small firms, it limits their capacity to absorb the external information if the education level of entrepreneurs or staff is low. The firm efficiency is strongly connected to the state of knowledge, technology and ordering preferences. It can be increased by trading off the production, transaction and organisation costs. Furthermore, the dynamic efficiency or innovation is characterised by the shifts of knowledge and renewing perceptions of new opportunities (Nooteboom, 1993).

Nooteboom (1993) also argues that the generic firm size effects apply to both parties and their threshold costs of transactions. Transaction costs in small firms denote in terms of the effects of scale (small volume), scope (few products), experience and limited capacity for learning. Therefore, on the whole, transaction costs are relatively higher for small firms. Similarly, threshold costs of contact, contract and control are the same despite the firm size and hence relatively heavier for small firms.

\section{Research method}

\subsection{Research design}

According to Remenyi et al. (1998), the central premise of non-positivist research is that the researcher should be concerned with understanding the phenomenon in depth and that the understanding should result from attempting to find tentative answers to questions such as 'what', 'how' and 'why'. In designing the research, a case study approach is chosen because, as Yin (2003) argues, this type of approach is a preferred empirical inquiry strategy when 'what', 'how' or 'why' questions are posed, when the researcher has little or no control over events and when the focus is on a contemporary phenomenon within its real life context.

This study as a whole uses a multiple case design because the evidence from multiple cases is often considered more compelling and the overall study is therefore regarded as being more robust (Yin, 2003). Furthermore, in a multiple case study, both discovery and theory development are found within the same case study. Each individual case reveals a discovery, but the replication across cases also adds up to a significant theoretical breakthrough (Yin, 2003). The reasons for choosing eight different cases are the appropriateness and availability of participants, the lack of demand for an excessive degree of certainty and finally the necessity of satisfying external validity.

\subsection{Unit and level of analysis}

The focused unit of analysis for the study is the Gnosjo industrial district because it is a well-known industrial district in Sweden and in the world as well as its viability is important. The use of the firm as the level of analysis stands on the grounds that the firms seeking competitive advantage are the main actors in an industrial district.

\subsection{Data collection}

The present study is based on three different sources of evidence; namely, interviews, documentation and archival records. To increase the overall quality of case study, multiple sources of evidence are used because they essentially provide multiple measures 
of the same phenomenon and thus increase the construct validity of study (Yin, 2003). The interviews are an essential source of evidence conducted through questioning the local entrepreneurs and other stakeholders mentioned in the research sampling frame shown in Table 1. A focused and semi-structured theme interview technique is used where well-informed respondents are deeply interviewed for a short period of time; e.g., two hours in each session. The interviews remain open-ended and assume a conversational manner, but the researcher is more likely to be following a certain set of questions derived from the case study protocol. To increase the reliability of research, the case study protocol is designed as a major tactic that guides the researcher in carrying out the study.

Table 1 Sampling frame

\begin{tabular}{|c|c|c|c|}
\hline Name & Type & Interviewee & Brief history \\
\hline $\begin{array}{l}\text { ELBE AB } \\
\text { (Hillerstorp) }\end{array}$ & Manufacturing & $\begin{array}{l}\text { Marketing } \\
\text { director }\end{array}$ & $\begin{array}{l}\text { Family-owned firm run by the second } \\
\text { generation of family. Produces display, } \\
\text { shop fittings, standardised assortment } \\
\text { and assembly. IS09001 certified. Its } \\
\text { daughter firm, Elbe Platteknik, is in } \\
\text { Denmark. }\end{array}$ \\
\hline $\begin{array}{l}\text { Gnosjo Municipality } \\
\text { (Gnosjo) }\end{array}$ & Municipality & Mayor & $\begin{array}{l}\text { Municipality with approximately } \\
350 \text { manufacturing firms and } \\
10,300 \text { inhabitants. }\end{array}$ \\
\hline $\begin{array}{l}\text { Haga Metall } \\
\text { (Kulltorp) }\end{array}$ & Manufacturing & CEO & $\begin{array}{l}\text { Family-owned firm. Manufactures } \\
\text { single component and assembles } \\
\text { several components. Provides its } \\
\text { customers with machining capacity. } \\
\text { IS09002 and IS } 014000 \text { certified. }\end{array}$ \\
\hline $\begin{array}{l}\text { Industrial } \\
\text { Development Centre } \\
\text { (Anderstorp) }\end{array}$ & $\begin{array}{l}\text { Development } \\
\text { centre }\end{array}$ & $\begin{array}{l}\text { Project } \\
\text { manager }\end{array}$ & $\begin{array}{l}118 \text { firms and three local Metal } \\
\text { Industry Worker's Unions hold shares. }\end{array}$ \\
\hline $\begin{array}{l}\text { Manufacturing } \\
\text { Industry Union } \\
\text { (Gislaved) }\end{array}$ & Union & Representative & Industry labour union, Jonkoping. \\
\hline $\begin{array}{l}\text { Pelop AB } \\
\text { (Gnosjo) }\end{array}$ & Manufacturing & CEO & $\begin{array}{l}\text { Small family-owned firm. Expertise in } \\
\text { metal and plastic materials. }\end{array}$ \\
\hline $\begin{array}{l}\text { Peltor AB } \\
\text { (Varnamo) }\end{array}$ & Manufacturing & $\begin{array}{l}\text { Purchasing } \\
\text { director }\end{array}$ & $\begin{array}{l}\text { Produces hearing protection and } \\
\text { communication products. Part of the } \\
\text { American Aearo Corp., a world leader } \\
\text { in personal safety equipment. IS } 09001 \\
\text { certified. }\end{array}$ \\
\hline $\begin{array}{l}\text { SM Johannesson } \mathrm{AB} \\
\text { (Anderstorp) }\end{array}$ & Manufacturing & CEO & $\begin{array}{l}\text { Develops products for the air filter } \\
\text { industry. Market leader in Europe. Its } \\
\text { daughter firm, Defem System, with } \\
\text { products for IT/Telecom cable } \\
\text { channelling, is ISO9001 certified. }\end{array}$ \\
\hline
\end{tabular}

The documentary information takes many forms of administrative documents such as public and internal documents as well as published websites of the participants. Existing literature and reports as archival materials about the Gnosjo region are another useful source of information. The most important use of systematic searched documents and archival records is to corroborate and augment the evidence from interviews. Only when 
all of the evidence produces a consistent picture is the researcher satisfied that a particular event has actually occurred in a certain manner.

To reduce the likelihood of bias for substantiating a preconceived position by the researcher, the preliminary findings in the data collection phase are reported to critical colleagues who offer some alternative suggestions for data collection.

\subsection{Data analysis}

In this study, the preferred analytic strategy relies on theoretical proposition that the Gnosjo industrial district is a viable corporation. This strategy is used in practicing the Cross-case synthesis technique for analysing the data of a multiple case study. The analysis involves two stages: the within-case analysis for each case separately to identify unique patterns within the data for that single case and the cross-case analysis for all cases jointly to search for common patterns between cases. By examining pairs of cases and categorising the similarities and differences, patterns begin to emerge and lead to a conclusion. When a pattern from one data type is corroborated by the evidence from another, the finding is stronger. When the evidence conflicts, then a deeper probing of the differences is necessary to identify the cause or source of conflict. In all cases, the evidence is treated fairly to produce an analytic conclusion answering the original research question.

\section{Results}

The prospering Gnosjo region contains the Gnosjo municipality as its centre and the other municipalities of Gislaved, Vaggeryd and Varnamo. The local industries of the region are recognised by their small businesses and sufficient critical mass of entrepreneurs that enable them to adapt quickly to the changing market requirements and new trends in the world. There is also a long tradition of cooperation and network formation in place that promotes the industrial success. Interestingly, a similar industrial culture pervades nearby towns such as Anderstorp and Hillerstorp. There are about 1,500 industrial firms in the region mostly specialised in metal, plastic and finishing products. The firms mainly serve the automobile and area's own manufacturing industries. Moreover, the production system is more labour-intensive rather than knowledge-intensive. The manufacturing, mining and quarrying industry in Gnosjo is highly labour-intensive. The trade, transport and communication sector and the health and social work sector are in the next positions. However, the unemployment rate is relatively low; in January 2003 it was only $1.5 \%$ in Gnosjo, while $2.7 \%$ in Jonkoping and 3.6\% in Sweden, respectively (Statistics Sweden, 2003). The Gnosjo region is top of the Swedish league table for growth alongside the Stockholm region.

What has maintained the dynamism of Gnosjo has been a constant emphasis on quality, productivity and reliability married to a strong family ownership tradition. Although the industrial strength of Gnosjo has naturally spawned a supporting service sector and a welter of trading firms, there is less evidence of an entrepreneurial culture perpetuating itself through the establishment of new firms. The encouraging news is that the strengths of the region show no sign of eroding (Rock, 1995). Rock (1995) argues that the entrepreneurs have been discouraged by an onerous tax system, rigid labour 
market laws and an overstress on the large business and public sector. However, the Gnosjo region has long served as a model for entrepreneurial skills and business success.

The corporate structure of the region consists mainly of small family-owned firms. Its industries boast the production expertise as well as an impressive array of machinery and technological equipment. The automation and information technologies as well as the efficiency and effectiveness measures are well implemented and several firms also have their own products on the global market.

The level of on-the-job training and tacit knowledge is extremely high, but the level of formal education is still low in the region. The small firms mostly favour the informal tacit and non-codified knowledge system and the learning by watching and doing fashion through personal network, while the medium-sized and large firms have more formal training programmes for management and workforce. However, some stakeholders have already been developed for learning modes in the public sector for professional level growth as an important part of the competitiveness that is in a transition phase of internationalisation. The Vaxjo University is an example that focuses on the entrepreneurship and small firms. Directly adjacent to the Jonkoping University, a new science park has been set up that provides a creative growth environment for future cutting-edge firms. Additionally, in cooperation with the National Institute for Working Life and regional universities of Vaxjo and Jonkoping, a learning network programme has been implemented by the Industrial Development Centre of Gnosjo. It has based this programme on the organic social networks that is gaining an institutional status in the region. Hogskolan pa Hemmeplan, run by all municipalities, represents the institution of formal education by offering university courses and continuing education programmes. The vocational training units for unemployed persons are also located in all municipalities and most training courses are managed by a state-owned educational institute called AmuGruppen AB (Brulin, 1998). The establishment of the Gnosjo Education Centre in 1997 has also enriched the learning environment by offering a wide range of courses and conferences.

In the Gnosjo region, the manufacturing industries are strongly dominated by the price-competing firms with a clear objective for profit maximisation. While the competence in each firm is not very high, the collective competence within the fields of metal and plastic productions is quite high (Brulin, 1998). A kind of mutual dependence within a tight local network is developed that makes the border between competition and cooperation fluid (Karlsson and Larsson, 1993). Although the businesses cooperate, at the same time, they compete with each other to promote their own technology and choose the direction that is most beneficial to them (Mione, 2009). However, an overall restructuring is in progress and in just a few years many family-owned firms were sold to the Swedish or foreign investment or venture capital firms and a number of firms closed their factories. The reasons to sell the firms are mainly related to the desire for efficiency expressed as the highest possible firm value. Firstly, the owner had to pay new taxes on the family wealth and fortune, secondly, passing the heavy load of running a firm over to the next generation was troublesome and thirdly, the owner ran out of knowledge to run the business when it reached a certain stage of growth (Wigren, 2003).

The social capital of Gnosjo appears as a strong, traditionally profitable entrepreneurship that attracts globally operating industries. The entrepreneurs have traditionally preferred the bootstrapping to venture capital and the local banks to international funding as the main source of investment. According to Johannisson (2002), the distinct features of special entrepreneurial atmosphere in the region are the 
cooperation, solidarity and shared mutuality among the entrepreneurs and their curiosity about everything new. The other manifests of the spirit of Gnosjo are that the people have a non-negative attitude towards entrepreneurship and the public authorities steer their actions regarding the needs of businesses. The attendance of eight entrepreneurs' representatives out of 41 in the municipality council guarantees that their views are considered in decision making. Hence, the entrepreneurship in Gnosjo is a collective socio-economic action (Johannisson, 2004).

\section{Discussion}

The problem of Sweden and its large firms according to Brulin (1998) is that they have not nourished a structure of supportive SMEs. There is a lack of creative territorial energy around many of the large firms and the Gnosjo region is an exception. However, the continuity of business in this industrial district in the future is about to be a serious question. Therefore, most common goals of most interviewed stakeholders for the future are the top professional skills development, firm growth and cost efficiency improvement.

Because of the demand for intelligent production technology, skilled workforce is required in all types of industries. However, the deficiency of skilled workforce in this region is a continuous problem for two reasons. Firstly, people are not very interested in moving into the region due to a lower level of salaries and a higher level of accommodation cost. Secondly, most SMEs will have to change their management in the future as they deal with issues including the high risk of intergenerational transition that hamper the smooth succession to the next generation. Simply, the formally educated heirs of some entrepreneurs have no wish to stay in the region and the informally trained ones have inadequate knowledge to work in the industrial atmosphere. Therefore, many entrepreneurs are willing or planning to sell/merge or have already sold/merged their businesses to other local or international firms. Some of the sold/merged businesses produced some financial capital that has been invested in the region by starting a new business that has increased the social capital of the industrial district. The changing attitudes towards external ownership affect both economic and social lives (Wigren, 2003) as a completely different financial growth is resulted. Hence, the governance structure of industries will change when the externally-owned firms expand their exchanges.

The process of changing attitudes from preferring tacit knowledge to more advanced education levels has been further supported by the fact that the owner/managers have realised the value of knowledge in creating the efficiency and competitiveness. The core skills such as research and development as well as management should be placed into the region in order to maintain the power of industries. Furthermore, the interaction between locally- and externally-owned firms makes new opportunities to learn about the management styles, processing modes, standardisation and international business.

In light of the ongoing trends in technology and restructuring, the demands on competitiveness and international recognition have rapidly intensified. Considering that most firms in Gnosjo are small and only a small part survives based on a product of its own, there are many reasons to review the potential for bringing more firms into the region that have some products of their own on the international market. In this respect, there is a key link between many SMEs in the region and the resources available in the 
universities and especially industrial research centres. Brulin (1998) argues that bringing external partners into a region such as Gnosjo is not without any problem and proposes that external partners must not take over the process of territorial development thereby threatening to drain it of indigenously created energy.

The stakeholders are bodies separated on a continuum based on their local and global activities. The small firms are doing business locally, the medium-sized firms are acting both locally and internationally and the large firms are more connected to the global environment. Figure 1 shows the inter-firm relationships in the Gnosjo industrial district.

Figure 1 Transactions in the corporation of the Gnosjo industrial district

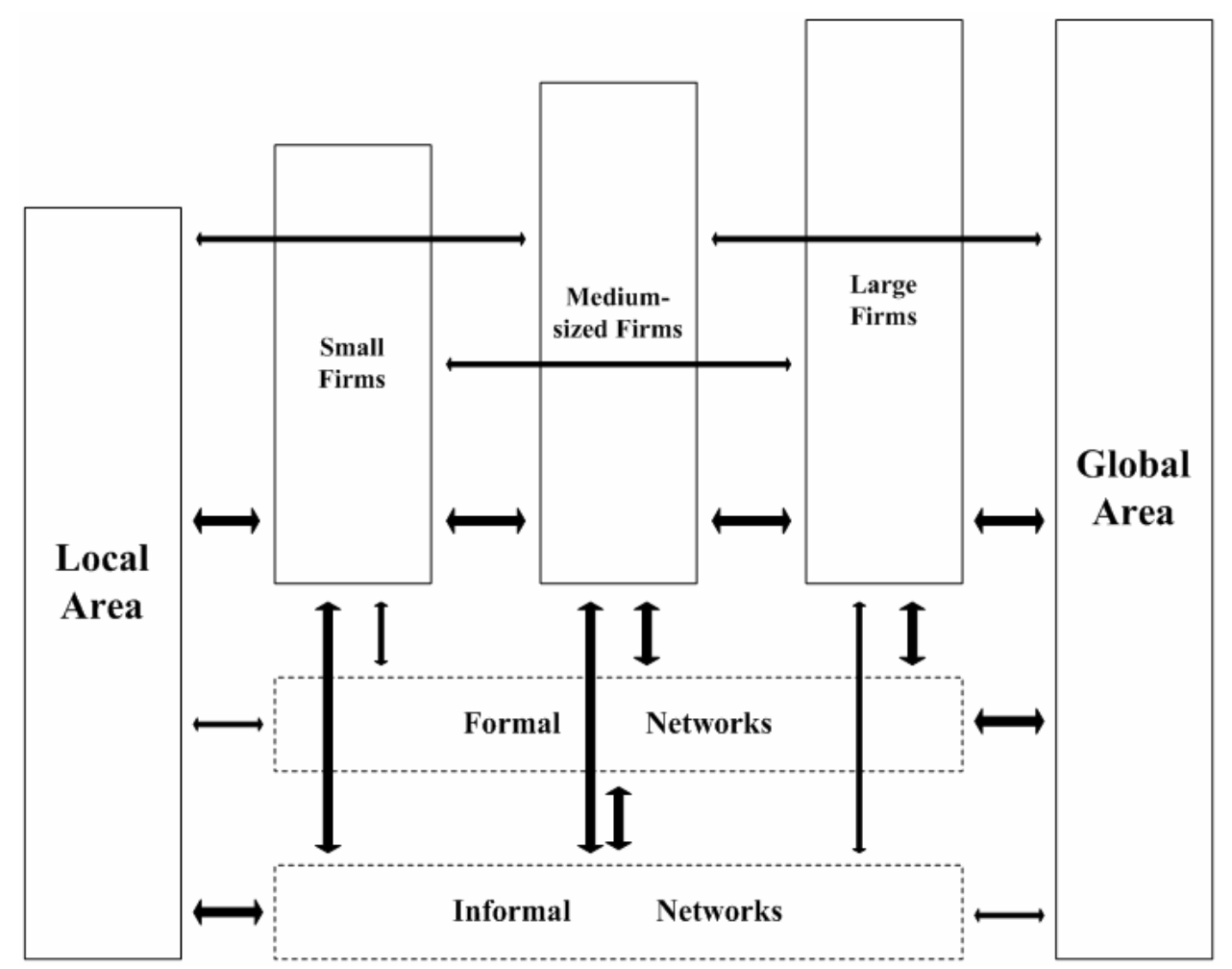

The transaction specificity of investments in products and processes is twofold in the value adding chain. First, there are SMEs that are producing within the region and competing by developing more effective production methods and keeping up to the customers' expectations, which are mostly local or based on some recurrent business relationships outside of the region. The second type of transaction-specific investments is conducted by the large firms that are aiming at recurrent long-term exchange relationships, but competing on the global market with high technology and top quality products and thus increasing their competitiveness cumulatively. It requires the outsourcing of labour-intensive parts of the production processes, concentrating on core capabilities and recruiting educated workforce capable of learning, absorbing and adopting new knowledge continuously. However, the relational contracting dominates the business operations within the region. 
The make or buy decisions in the region are made with respect to long-term commitments relying on the trust-based embedded personal, economic and social relations in the formal and informal networks between firms. International transactions also take place when the required product or service is unavailable on the domestic market. The process of supplier selection considers the criteria such as price, quality and trust and the reliability of a potential supplier is usually checked by the fact that people know each other through formal and informal networks. Consequently, the medium-sized firms have more stable long-term supplier relationships. The externally-owned firms usually do not treat the local suppliers differently from other suppliers regarding the price, quality and service. Some reasons for selecting local suppliers are introduced as their proximity, local language, knowledge about each other and the running system as well as their approach to solving the problems. The mutual commitment and trust in the business exchange make the 'personal chemistry fit' (Johannisson, 2002) that eliminates the need for a formal contract. In categorising the preconditions to high-trust system, Sabel (1993) introduces the cooperation model as a growth strategy that pinpoints both formal and informal networks. This setting is clearly apparent in the Gnosjo region and therefore it is found that trust is a remaining aspect of the calculative interactions and the revealed opportunistic behaviour is very costly in the region.

Since the region is an equal community (Wigren, 2003), the power distribution has more advanced methods. In the business life, the power distribution is obviously different in locally- and externally-owned firms. The local SMEs not only strive at long-term relationships within the region, but also use the outside suppliers with well-formulated contracts for economic and efficiency reasons. The externally-owned firms use the local social capital and competent suppliers only when the price, quality and service meet their requirements. However, the power relationships are exhibited in the prevalence of asymmetric subcontracting relations so that the highly specialised small firms show a higher dependency on their customers (Serarols i Tarres et al., 2008).

The embeddedness of different stakeholders in the formal and informal networks describes the supportive aspect of the society for entrepreneurial activity. The formal and informal networks in a tight society cannot be clearly separated because they are intertwined (Granovetter, 1992). The roots of economic life in Gnosjo have also appeared in the layer of informal networks and the firms are concerned about the mutual benefits of deeper embeddedness. In this tandem, the small firms diffuse the tacit knowledge in developing the industrial knowledge, but they have less time for taking care of the industrial networking. The medium-sized firms have the heaviest responsibility for distributing the regional work orders to the small firms and receiving the interaction benefits from the large firms. The global interactions are more obvious in the level of large firms, although they take advantage of an elaborate local platform to approach the global market and have their own share of changing the society at least in the layer of formal networks such as the association of entrepreneurs, unions, development centres and municipalities.

In a traditionally strong classless society such as Gnosjo, the legal systems are highly substituted by shared ideals and genuine relationships. It reflects the stability or inertia in this society where the routines, norms and ideals appear in both formal and informal networks. This awareness about the importance of general social embeddedness of economic activity (Johannisson, 2002) is a typical aspect of the entrepreneurial spirit in Gnosjo. 


\section{Conclusions and future research}

The purpose of this research is to evaluate the viability of the Gnosjo industrial district on the competitive market using the conceptual framework of corporation. The relevance of this approach is based on the specific hierarchies and factors affecting the transaction costs of exchange in the industrial district.

The specific qualities of stakeholders in the Gnosjo region are connected to their visions for the future development of the firms and industries they run. Although it is said that the regional strategy is to become a national centre for polymers and cutting technology, the views of firms reveal that there is no mutually expressed regional strategy that could be a guideline for the public authorities to mould the infrastructure of the region. However, the deeply rooted and embedded formal and informal relationships based on trust increase the learning benefits and reduce the uncertainty and thus the transaction costs. The most common goals among the stakeholders are of an economic nature; namely, the high professional skills development, firm growth and cost efficiency improvement. Furthermore, the entrepreneurs of Gnosjo are positively glowing with the professional pride and job satisfaction. Therefore, it improves the competitive advantage to be a part of a transaction cost reducing social network.

Whether the firms make or buy the required supplies depends on their relations to the region and transaction specificity. An existing trust-based network between the economy stakeholders eases the stages of a transaction (contact, contract and control) so that there are fewer costs to incur when the transactions are recurrent.

The outsourcing of operating processes to the industries of the region is connected to the labour- or knowledge-intensiveness of the industry. It is of high importance in the Gnosjo industrial district and therefore it probably increases the value of the region as an interesting environment for the knowledge-intensive industries as long as it continues to encourage formal education for the youth and working people in the region.

In this industrial district as a viable corporation, all stakeholder groups act preferably in a profitable, effective and productive manner and take good care of the business and each others' economic and social well-being to add value to this organisational agglomeration so that the rationality behind this institution is the community entrepreneurship.

The distribution of power in the region has been in a transition phase for some time. Among specialised stakeholders, there is an asymmetrical distribution of information, but the infrastructure of knowledge distribution takes care of the general and specific requirements of each and every stakeholder group. The arenas for rational and irrational negotiations are mutually created and they facilitate the process where the organisations account for their actions, observe independent and mutual benefits and update the business account for the creation of vision and strategy in the region.

The Gnosjo industrial district has kept up its pace compared to the most successful industrial districts in Europe because of its unique entrepreneurial spirit and flexibility in the turbulent environment. These are deeply rooted in the surrounding society whose structure has a strong impact on the viability of businesses. However, the invasion of externally-owned firms interested in its strong social capital as well as increasing demands for innovation also challenge this region to maintain or improve the competitiveness of its industries. The increasing external ownership of firms changes the governance structure of industries and therefore the local entrepreneurs should be encouraged to continue the flexibly specialised business tradition by reducing the tax 
consequences of succession to the next generation and including the entrepreneurship education, consisting of learning methods, pedagogical processes and frames for education, in the educational system (Blenker et al., 2008).

In order to keep the transactions in a reasonable level, the outsourcing of labour-intensive processes should not be extended too wide. The actual power for self-organising the economic life should be kept locally or regionally in the hands of formal and informal networks of the entrepreneurs. Therefore, the main responsibility of the municipalities and industrial development centres is to provide SMEs with the infrastructure, educational system and information required to maintain the viability and growth potential of the region.

The findings of research can be utilised in the areas of regional development planning, policy making and entrepreneurship training. The relevant subjects for future research may include the development of bootstrapping and subsiding possibilities for the local entrepreneurs, reduction of tax to facilitate the succession to the next generation for the firms and introduction of ways to embed the international firms and their non-local personnel in the local formal and informal networks.

\section{Acknowledgements}

The author would like to acknowledge the reviewers' comments towards improving the quality of the paper.

\section{References}

Benton, L. (1992) 'The emergence of industrial districts in Spain: industrial restructuring and diverging regional responses', in Pyke, F. and Sengenberger, W. (Eds.): Industrial Districts and Local Economic Regeneration, International Institute for Labour Studies, Geneva.

Blenker, P., Dreisler, P., Færgemann, H.M. and Kjeldsen, J. (2008) 'A framework for developing entrepreneurship education in a university context', International Journal of Entrepreneurship and Small Business, Vol. 5, No. 1, pp.45-63.

Brulin, G. (1998) 'How to shape creative territorial energy: the case of the Gnosjo region', Concepts and Transformation, Vol. 3, No. 3, pp.255-269.

Furst, D., Schubert, H., Rudolph, A. and Spieckermann, H. (2001) 'Regional actor networks between social capital and regional governance', Connections, Vol. 24, No. 1, pp.42-67.

Granovetter, M. (1992) 'Problems of explanation in economic sociology', in Nohria, N. and Eccles, R.G. (Eds.): Networks and Organizations: Structure, Form and Action, Harvard Business School Press, Boston.

Johannisson, B. (2002) Entrepreneurship as a Collective Phenomenon, available at http://www.vxu.se/ehv/filer/forskning/entreprofil/publikationer/collective_phenomen.pdf (accessed on 15 August 2009).

Johannisson, B. (2004) 'Entrepreneurship in Scandinavia: bridging individualism and collectivism', in Corbetta, G., Huse, M. and Ravasi, D. (Eds.): Crossroads of Entrepreneurship, Kluwer Academic Publishers, Dordrecht.

Johannisson, B., Ramirez-Pasillas, M. and Karlsson, G. (2002) 'The institutional embeddedness of local inter-firm networks: a leverage for business creation', Entrepreneurship and Regional Development: An International Journal, Vol. 14, No. 4, pp.297-315. 
Karlsson, C. and Larsson, J. (1993) 'A macro view of the Gnosjo entrepreneurial spirit', Entrepreneurship and Regional Development: An International Journal, Vol. 5, No. 2, pp.117-140.

Mione, A. (2009) 'When entrepreneurship requires coopetition: the need for standards in the creation of a market', International Journal of Entrepreneurship and Small Business, Vol. 8, No. 1, pp.92-109.

Nooteboom, B. (1993) 'Firm size effects on transaction costs', Small Business Economics, Vol. 5, No. 4, pp.283-295.

Remenyi, D., Williams, B., Money, A. and Swartz, E. (1998) Doing Research in Business and Management: An Introduction to Process and Method, Sage publications, London.

Rock, M. (1995) 'Found: Europe's business hotspots', Director, Vol. 49, No. 3, pp.48-55.

Sabel, C.F. (1993) 'Studied trust: building new forms of cooperation in a volatile economy', Human Relations, Vol. 46, No. 9, pp.1133-1170.

Sengenberger, W. and Pyke, F. (1992) 'Industrial districts and local economic regeneration: research and policy issues', in Pyke, F. and Sengenberger, W. (Eds.): Industrial Districts and Local Economic Regeneration, International Institute for Labour Studies, Geneva.

Serarols i Tarres, C., Co, M.J. and Spohn, D. (2008) 'A transaction cost approach to analysing industrial districts', International Entrepreneurship and Management Journal, Vol. 4, No. 2 , pp.235-252.

Sjostrand, S.-E. (1992) 'On the rationale behind irrational institutions', Journal of Economic Issues, Vol. XXVI, No. 4, pp.1007-1040.

Statistics Sweden (2003) Labour Market, available at http://www.scb.se (accessed on 15 June 2003).

Trigilia, C. (1992) 'Italian industrial districts: neither myth nor interlude', in Pyke, F. and Sengenberger, W. (Eds.): Industrial Districts and Local Economic Regeneration, International Institute for Labour Studies, Geneva.

Wigren, C. (2003) The Spirit of Gnosjö: The Grand Narrative and Beyond, Jonkoping International Business School, Jonkoping.

Williamson, O.E. (1979) 'Transaction cost economics: the governance of contractual relations', Journal of Law and Economics, Vol. 22, No. 2, pp.233-262.

Yin, R.K. (2003) Case Study Research: Design and Methods, 3rd ed., Sage Publications, Thousand Oaks. 